\title{
Two Perspectives on the Language of Special Needs Computing: towards a shared view
}

JANE KATHERINE SEALE

School of Occupational Therapy and Physiotherapy, Southampton University, Highfield, Southampton SO17 1BF, UK

ABSTRACT This paper reviews and examines the language used in literature that describes the educational and therapeutic use of microcomputers with people who have special needs. In the language of special needs computing two perspectives are identified. One perspective focuses on the microcomputer technology while the other focuses on the microcomputer user. While the language of both perspectives acknowledges the value of microcomputers, each perspective moves towards an acknowledgement that microcomputer use needs to be placed in an environmental context. This move in both language sets reflects an increasing focus on the potential barriers to microcomputer use.

\section{Introduction}

Microcomputers have been used in education and therapy for the past 15 to 20 years (Seale, 1993). The purpose of this paper is to examine the literature that describes the educational and therapeutic use of microcomputers with people who have special needs. A particular emphasis will be given to the language used in special needs computing literature. It has been argued recently that in all forms of media the general history of disability representation is one of oppressive or negative forms (Hevey 1993). Casling (1993) argues that we live in language and through language, and it is in language that our unconscious drives are situated. In our literature we can often observe two distinctly different perspectives of disability. One is that society is sympathetic and caring while the second is that disabled people find themselves living within 'viciously oppressive social structures that deny the most basic of human rights'. This paper seeks to identify whether literature describing the educational and therapeutic use of microcomputers with people who have special needs can also be seen to reflect differing perspectives.

\section{The Language of Special Needs Computing}

In an examination of educational technology's metaphors, Karovsky (1989) discussed how they might reflect a consumerism in which technology encourages our 
own greed. In a market society where 'more is better', individual's needs are transformed into demands for goods and services. An examination of the literature describing the use of microcomputers in the field of special needs reveals a small vein of consumerism. For example, in describing teachers and microcomputer use, Stowitschek \& Stowitschek (1984) describe how special educators have taken the lead in 'promoting' uses of new technology. Semmel et al. (1984) talk of teachers being 'fuelled by the powerful forces of the market place'. Goldman et al. (1987) stated that the popular press was full of anecdotal stories and 'hyperbolic sales pitches' aimed at capturing the educational market.

\section{Focus on the Microcomputer Technology}

While an initial examination of the language of special needs computing reveals a small emphasis on consumerism further investigation reveals three language sets that place a greater focus on the capabilities of microcomputer technology:

- the microcomputer as a prosthesis;

- microcomputers and metaphors;

- the microcomputer as an innovation.

\section{The Microcomputer as a Prosthesis}

Microcomputers have been heralded as the new saviours for disabled people because they are believed to have a corrective function, helping disabled people do what they previously could not. Foulds (1982) stated that the microcomputer could be used to extend the existing physical abilities of the disabled person in much the same way that eyeglasses extend the visual acuity of the population in general. Emphasis is placed on the enabling potential of microcomputers. A common description that has been applied to microcomputer technology is that of a 'prosthesis'. Chapman (1982), for example, described the microcomputer as a 'prosthesis for man's neurology'; while Cain (1984) wrote about the 'prosthetic communication' applications of computers. Images that are often associated with that of the microcomputer as a prosthesis are images of freedom, emancipation and expanding horizons.

This new technology can emancipate the handicapped and help to open up the horizons of many children whose communication and interaction with the outside world were previously very limited. (Southgate, 1985.)

\section{Microcomputers and Metaphors}

Karovsky (1989) argued that metaphors give us new ways to interpret our experiences, to perceive our lives and therefore our realities. In the special needs computing literature early metaphors focused on the microcomputer as a product. Goldenberg (1984), for example, postulated four metaphors for microcomputers. 


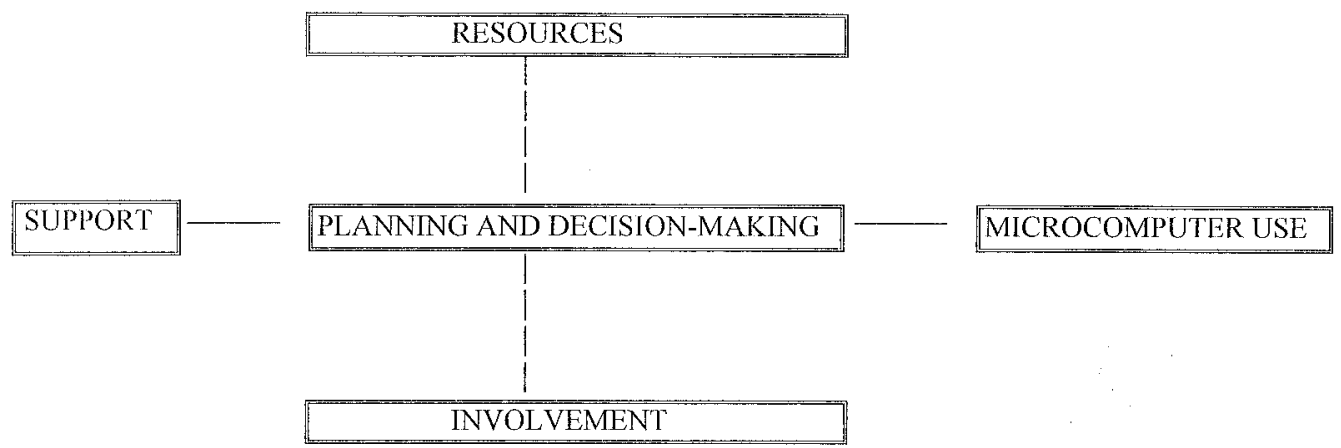

FIG. 1. The cruciform as a metaphor to describe microcomputer use.

- The microcomputer as a tutor: taking the active role of teacher and dictating what is to be learned.

- The microcomputer as a mirror: providing feedback that reflects performance.

- The microcomputer as eyeglasses: facilitating and widening acuity.

- The microcomputer as a blackboard: just one tool in many.

Later metaphors, however, have focused on the process of learning with microcomputers and have used images of the microcomputer as a 'learning vehicle' (Baker, 1985). Clamp (1983) described the microcomputer as a 'vehicle for the acceptance of new ideas'; while Semmel et al. (1984) talked of the microcomputer as a vehicle through which differences between pupils will be markedly reduced. Busby et al. (1988) state that the microcomputer is a vehicle to aid learning and improvement of social skills.

If the microcomputer is a vehicle, then the people who use microcomputers can be seen to be embarking on journeys or expeditions. Collins (1989) postulated that an 'exploration or guided tour' was potentially a valuable metaphor for microcomputer use in special education because it incorporated the concepts of exploring an environment and the learner playing a central role in that exploration.

The travel metaphors are useful in that they de-emphasise the role of the microcomputer and place some focus on the user of the microcomputer. Other metaphors also attempt to de-emphasise the role of the microcomputer, but focus beyond the user to broader environmental issues. For example, in her description and interpretation of microcomputer use in nine Adult Training Centres, Seale (1993) used an extended metaphor of a cruciform. She argued that it might be useful in helping us to describe the barriers to successful microcomputer use (Fig. 1).

Imagine you want to create a cross out of two pieces of wood. One obvious method is to place one piece vertically and the other across it horizontally. One might secure the two pieces together with a nail in the middle. Without a nail the cross would fall apart. If we apply this idea to microcomputer use in adult special 
education the 'nail' that secures effective microcomputer use is planning and decision-making. Through planning and decision-making:

- all relevant parties are involved on an equal footing;

- resources to support computer use are earmarked and allocated;

- support from everyone involved is gained and maintained;

- microcomputer use is linked to environmental conditions such as accessibility.

The cruciform as a metaphor was developed specifically to interpret microcomputer use in Adult Training Centres. The barriers to successful microcomputer in Adult Training Centres were factors such as Resources, Support, Involvement and Planning. These might equally be barriers that are experienced in our wider society.

\section{The Microcomputer as an Innovation}

Seale (1993) noted that the discussion of microcomputers was frequently framed with the language and vocabulary of innovation. Goldman et al. (1987), for example, considered that microcomputer technology was the latest in a series of 'instructional innovations to be considered as an answer to all problems'. Goodyear \& Barnard (1982) discussed the practicalities surrounding the adoption in schools of an innovation like the microcomputer. Associated language often links the notion of 'revolution' to that of 'innovation'. For example, Cain (1984) considered that microcomputer technology represented the most 'revolutionary innovation' yet developed in the field of education. The language of innovations is interesting because it contributes to the idea of 'promoting a product'. A product is a lot more appealing if it is an 'innovation'.

The language of innovation, however, can be used to look beyond the product and look at factors that influence both access to and use of the product. Seale (1993) argued that if the microcomputer is an innovation then we could use theories and knowledge of innovations to understand what factors have an influence on the effectiveness of microcomputer use. Specifically, she focused on theories that identified successful strategies for implementing innovations. She argued against strategies for implementing microcomputer use that focused solely on the microcomputer (innovation-focused) in favour of strategies that placed importance on the environment in which the microcomputer was being implemented. Such strategies should look beyond the microcomputer itself to the factors that combine to create the context in which the microcomputer is placed, such as user interest and available training.

While the three language sets have focused primarily on the microcomputer we have seen that there is a move towards exploring the language sets further in order to place microcomputer use in an environmental context and identify potential barriers to computer use. This move is reflected in the literature that focuses on the users of microcomputer technology. 


\section{Focus on the Users of Microcomputer Technology}

The majority of literature discussing special needs computing tends to be written by teachers, carers, researchers, psychologists, therapists, programmers and engineers. There is an important, if small, section of the literature that will be described below that is written by the users of microcomputer technology. An analysis of this literature reveals four main foci of attention:

- the independence offered to people with disabilities by microcomputers;

- the problems experienced in using microcomputer technology;

- beliefs that the value of microcomputers is over-emphasised;

- the barriers that using a microcomputer has not managed to break down.

\section{The Independence Offered to People with Disabilities by Microcomputers}

In 1989 Vincent collated the experiences of disabled computer users who attended various colleges around the country. For example, Scott (1989), reported that the computer meant a lot to her because it gave her the ability to get on without having to ask people to do her paper work for her all the time. Crowe (1989) explained how he felt he had been given a new lease of life, which provided him with the ability to express his individuality with almost the same freedom as an able-bodied person. Emery (1993) describes how technology has changed her life from one of complete dependence and means that she will not be so dependent on other people, 'technology equals freedom' she stated.

John Prestwick (1994) makes an interesting statement that reflects the opinion that disabled people do not need to 'catch up' with everyone else in order to achieve independence, simply that microcomputers need to 'catch up' with people who have disabilities in order to offer opportunities for independence.

When I first became disabled there was nothing to assist me, I couldn't even switch an alarm bell on. I had no movement at all. Now technology has caught up with my disability and I'm able to have full control of my environment without help from anyone.

\section{The Problems Experienced in Using Microcomputers}

Rampton (1989) reports how he spent many frustrating hours getting to grips with his Amstrad 1512. He sums up by saying that given the problem he had with his microcomputer he would not have been able to use his microcomputer without the support of his college. Haines (1989), a history student, comments on how his portable computer ceased to be so portable once he had added all the extras required to use it effectively. He admits that he now does not take his computer to lectures, but finds a tape recorder more useful. Experiences such as these suggest that people need support in using their microcomputers, and that the microcomputer equipment used may not always be suitable or appropriate. 


\section{Beliefs that the Value of Microcomputers is Over-emphasised}

Paul Fisher (1993) interviewed John McFarlane, Director of the Computability Centre for The Guardian Newspaper. He describes John's reaction to the 'gee whiz' noises he was making to all the computer devices he was being shown.

Here are electronic miracles and I made the correct gee-whiz noises. McFarlane warned me against it, because his message is that there's nothing extraordinary about such computer peripherals. Seeing them as specialised let alone miraculous, is discriminatory in that it emphasises the otherness accompanying disability. Anyway technosolutions are often simple.

Smith (1989) and Ashton (1989) make some very interesting comments which serve to reinforce the idea that no matter how valuable microcomputers are, the primary focus should perhaps be on the people who use microcomputers and not the microcomputers themselves.

\section{Smith states:}

Technology is always going to be crucial importance to me, but it isn't everything.... In my view technology, used with care and the right kind of support, can help towards independence but over-emphasis on it can smother an individual's resources and only lead in the end to further limitations. (Smith, 1989, p. 190)

Ashton writes:

When folk talk to me about my job they exhale lungfulls of breath looking at the computer and printer and assume that working these machines constitutes the interesting and skilful part of my job. It doesn't. (Ashton, 1989, p. 193)

Dorcas Mundy (1993), a reporter for Ability magazine noted there is no hint of complacency or satisfaction with the technical status quo.

Technology must move forward in helping people to communicate.

This statement reflects a belief commonly held by people with disabilities that technology still has a long way to go.

\section{The Barriers that Using a Microcomputer has not Managed to Break Down}

The large majority of the article written by Emery (1993) is very positive about the role of technology in her life, but she does allude to some problems. The trouble with microtechnology and freedom, she wrote, is that you always need more. In her desire for more technology, Emery goes on to state that she knows that there are technological developments that people are not prepared to show her. Why this may be so is not discussed, but her statement suggest that while technology can be emancipating, it is only emancipating if one is 'given' access to it. Scott (1989) 
described her difficulties in gaining employment as a typist despite having undergone training to use a word processor.

One day we saw an advert in the paper asking for a disabled typist to work at DIAL. So we took a computer and I showed them what I could do. I typed some tables of numbers. When Jane came back to collect me, they wanted someone to do the filing and telephones and so the job was not suitable. It was strange they didn't put that they wanted this in the advert as well as the typing. I felt discouraged by this. (Scott, 1989, p. 181)

A statement by Professor Stephen Hawking (1994) highlights his dissatisfaction with the barriers that exist to prevent people obtaining voice synthesisers such as the one he uses.

People can only get synthesisers if they can raise the cash. That's not good enough. People should not be condemned to be just vegetables. People should campaign to get these devices on the NHS.

The experience of people with disabilities such as Emery and Scott suggests that using microcomputers provides a limited 'freedom' because the ability to express and demonstrate that freedom is still defined and limited by others, for whatever reasons.

\section{A Shared View}

Both perspectives of the language of special needs computing have acknowledged that the microcomputer can have an important role to play in increasing the independence of people with disabilities. For each perspective there has been a move towards de-emphasising the value of microcomputers in order to place emphasis on the factors which may help or prevent microcomputers from achieving their potential. Several academic authors who have focused on the societal barriers that prevent microcomputers from achieving their potential support this emphasis. Roulstone (1993), for example, states that little evidence exists to suggest that technology is redefining the notion of disability. Karovsky (1989) argues that by over-identifying with the tools (microcomputers) we lose sight of their social-cultural context.

\section{Conclusions}

An investigation of the language of special needs computing has identified two distinct perspectives. One perspective focuses on the microcomputer while the other focuses on the user. A discussion of these two perspectives has established that despite their obvious differences, they share some common ground. Both perspectives have acknowledged the contribution that microcomputers can make to our society and identified the need to place microcomputer use in an environmental context that acknowledges potential barriers to microcomputer use. This shared view requires us to think and talk in greater depth about how those barriers can be broken. Whatever solutions are derived and, however, the language of these solu- 
tions is framed the next issue to be addressed will probably focus on a social context. There is an increasing expectation that users will just get on and use microcomputers without much need for social reinforcement and feedback. This expectation is causing alarm amongst some educators. The vocabulary of alarm is couched in such terms as isolation and oppression, a far cry from liberation and innovation.

\section{REFERENCES}

Ashton, B. (1989) An individual experience-Beverley Ashton, in: A.T. Vincent (Ed.) New Technology, Disability and Special Educational Needs (Coventry, Empathy Ltd).

BAKER, F.B. (1985) Technology is not the issue: educational leverage for the microcomputer, Educational Technology, 25, pp. 54-56.

Busby, M. Jotham, D. Morgan, M. \& Field, B. (1988) Computers and adults with learning difficulties in the NewLink Project, Part One the Clay Model, Educare, 31, pp. 9-14.

CAIN, E.J. (1984) The challenge of technology; educating the exceptional child for the World of tomorrow, Teaching Exceptional Children, 16, pp. 239-241.

CAsling, D. (1993) Cobblers and songbirds: the language and image of disability, Disability, Handicap and Society, 8, pp. 203-210.

Chapman, B.L.M. (1982) Warnock in the light of new technology, Bulletin of the British Psychological Society, 35, pp. 454-455.

Clamp, S.J. (1983) Computer assisted learning and the less able, Remedial Education, 18, pp. $15-18$.

Collins, R.J. (1989) Computer Applications to Special Education, PhD Thesis, University of Keele. Crowe, A. (1989) An individual Experience-Andrew Crowe, in: A.T. Vincent (Ed.) New Technology, Disability and Special Educational Needs (Coventry, Empathy Ltd).

EMERy, I. (1993) Declaration of my independence, The Observer, June 6, p. 64.

FISHER, P. (1993) Enabling the disabled, The Guardian, June 24, p. 17.

Foulds, R.A. (1982) Applications of microcomputers in the education of the physically disabled child. Exceptional Children, 49, pp. 155-161.

Goldenberg, E.P. (1984) Computers in the special education classroom: what do we need, and why don't we have any?, in: J. A. MUllick \& B. L. MAllory (Eds) Transitions in Mental Retardation, Volume One: Advocacy (Baltimore, University Park Press).

Goldman, S.R. Semmel, D.S. Cosden, M.A. Gerber, M.M. \& Semmel, M.I. (1987) Special education administrator's policies and practices on microcomputer acquisition, allocation and access for mildly handicapped children, Exceptional Children, 53, pp. 330-339.

Goodyear, P. \& BARNARD, A. (1982) Microcomputers and special education: survey and prospects, in: C. SMITH (Ed.) Microcomputers in Education (Chichester, Ellis Horwood Ltd).

Haines, A. (1989) An individual experience-Andrew Haines, in: A. T. Vincent (Ed.) New Technology, Disability and Special Educational Needs (Coventry, Empathy Ltd).

Hawking, S. (1994) Communication for all, Ability, Issue 10, p. 6.

Hevey, D. (1993) The tragedy principle: strategies for change in the representation of disabled people, in: J. Swain, V. Finkelstein, S. French \& M. Oliver (Eds) Disabling BarriersEnabling Environments (Buckingham, Open University/Sage).

KArovsky, P. (1989) Educational technology's metaphors, British fournal of Educational Technology, 20, pp. 157-163.

Mundy, D. (1994) Not everyone can use a mouse, Ability, Issue 10, pp. 7-8.

Prestwick, J. (1994) You know how to whistle don't you? Ability, Issue 10, pp. 12-13.

RAMpton, T. (1989) An individual experience-Trevor Rampton, in: A.T. VinCENT (Ed.) New Technology, Disability and Special Educational Needs (Coventry, Empathy Ltd).

Roulstone, A. (1993) Access to new technology in the employment of disabled people, in: J. Swain, V. Finkelstein, S. French \& M. Oliver (Eds) Disabling Barriers-Enabling Environments (Buckingham, Open University/Sage). 
Scotт, M. (1989) An individual experience-Marisa Scott, in: A. T. Vincent (Ed.) New Technology, Disability and Special Educational Needs (Coventry, Empathy Ltd).

SEALE, J.K. (1993) Microcomputers in Adult Special Education: the management of an innovation, 2 vols. PhD Thesis, University of Keele. Semmel, M.I., Cosden, M.A., Semmel, D.S. \& Kelemen, E. (1984) Training special education personnel for effective use of microcomputer technology: critical needs and direction, Special Services in the Schools, 1, pp. 63-82.

Smith, A. (1989) An individual experience-Angela Smith, in: A. T. Vincent (Ed.) New Technology, Disability and Special Educational Needs (Coventry, Empathy Ltd).

Southgate, T. (1985) Microcomputer software: aids to communication, British fournal of Special Education, 12(4), p. 150.

Stowitschek, J.J. \& Stowitschek, C.E. (1984) Once more with feeling; the absence of research on teacher use of micros, Exceptional Education Quarterly, 14(4), pp. 23-39.

Vincent, A.T. (1989) New Technology, Disability and Special Educational Needs (Coventry, Empathy Ltd). 